and polyradiculitis, whereas aseptic meningitis has invariably had a benign course. Thus vigorous treatment is needed in cases of encephalitis and polyradiculitis, and, as shown by the present case and that described by Dr Cotter and others, plasma exchange may be the method of choice.

A PÖNKä

$M$ VON BONSDORFF M FÄRKKILÄ

Fourth Department of Medicine and Department of Neurology, University Central Hospital, Helsinki 00170, Finland ' Noah ND. Mycoplasma pneumoniae infection in the Pönkä A. Central nervous system manifestations associated with serologically verified Mycoplasma
pneumoniae infection. Scand f Infect Dis 1980;12:

"Pönkä A, Pönkä T, Sarna S, Penttinen K. Questionable specificity of Mycoplasma pneumoniae complement fixation test in patients with extra-

\section{Failure patterns after total hip arthroplasty}

SIR,-Mr John E Nixon's suggestion (15 January, p 166) that trochanteric osteotomy increases blood loss and operative time is unfounded $^{1}$; it does, however, avoid complications associated with inadequate exposure. A review from this unit showed that out of 14672 Charnley low friction arthroplasties dislocation occurred in 92 and only 16 required revision. ${ }^{2}$ It is heartening to report that of nearly 18000 operations performed since November 1962 only 730 had to be reviseda revision rate of just over $4 \%$ over 20 years. With improvements in the design and technique, introduced as a result of long term studies, the revision rate should be reduced still further.

Centre for Hip Surgery,

Wrightington Hospital,

Wigan,

' Del Sel H, Brittain G, Wroblewski BM. Blood loss and operation time in the Charnley low friction arthroplasty. Acta Orihop Scand 1981,52.197-200. Fraser GA, Wroblewski BM. Revision of the Charnley low friction arthroplasty for recurrent or irredu

SIR,-Mr J E Nixon (15 January, p 166) mentions thromboembolism as the most serious medical postoperative complication. There is increasing evidence that the type of anaesthetic used for hip surgery may contribute to the incidence of postoperative thromboembolism.

In a comparative study of spinal and general anaesthesia for surgical correction of fractured neck of femur McLaren et al ${ }^{1}$ showed a $31 \%$ postoperative mortality after four weeks in the general anaesthesia group compared with $3.6 \%$ in the spinal group. The causes of death were usually pulmonary embolism or bronchopneumonia.

The incidence of thromboembolism after major hip surgery has been studied by Modig (European Society of Regional Anaesthesia, Edinburgh, September 1982. Abstracts p 42-3). Patients requiring total hip replacement were randomly allocated to receive either epidural or general anaesthesia. The epidural was prolonged for 24 hours to provide initial postoperative analgesia. Patients in the general anaesthesia group received on demand narcotics for pain relief. No prophylactic anticoagulants were given. The incidence of deep vein thrombosis in calf and thigh veins was studied by phlebography, and the incidence of pulmonary embolism was determined by pulmonary perfusion lung scanning. In the general anaesthetic group $77 \%$ of the patients had deep vein thromboses and $33^{\circ}$, pulmonary embolism. In the epidural group $40 \%$ had deep vein thrombosis and $10 \%$ pulmonary embolism. The differences were significant. In addition, the general anaesthetic group had much larger deep vein thromboses.

Further studies are urgently needed to ascertain whether the continued use of general anaesthesia for major hip surgery can be justified.

Department of Anaesthesia,
Royal Victoria Infirmary,

J E Charlton

Newcastle upon Tyne NE1 4LP

' McLaren AD, Stockwell MC, Reid V'T. Anaesthetic techniques for surgical correction of fractured neck
of femur. A comparative study of spinal and genera anaesthesia in the elderly. Anaesthesia $1978 ; 33: 10-4$.

SIR,-Mr John E Nixon (15 January, p 166) assumes that total hip replacements will for the next 10 or 15 years involve the acceptance of acrylic cement by living tissue.

Since 1975, however, European surgeons have been using a "cementless" total hip replacement, and Professor G A Lord in Paris has experience of some 1200 cases (paper presented to the American Orthopaedic Association, Boston, 1981). Similar work in North America was delayed by strictures of the Food and Drug Administration, but the Madroporique (a name derived from the French for coral) system has been used by Dr D Ellis at Nanaimo, western Canada. Early results have been reported in the UK. Although the long term failure rate of this method is unknown, it will obviously be unrelated to cement acceptance.

\section{JILL Whitehouse}

Physiotherapy

' Kaye G. The cementless total hip arthroplasty. Physiotherapy 1982;68:394-8.

Reduced sinus arrhythmia in diabetic autonomic neuropathy

SIR,-Age is an important determinant of the magnitude of respiratory sinus arrhythmia. In her study on reduced sinus arrhythmia in diabetic autonomic neuropathy Dr S A Smith (4 December, p 1599) reports on the arrhythmia assessed from one deep breath ${ }^{2}$ rather than that based on the average of six consecutive breaths. ${ }^{1}$

We measured the magnitude of the inspiration-expiration difference ${ }^{1}$ in 43 diabetic patients at 9 and 11 am on the same morning. We calculated the inspiration-expiration difference of one ${ }^{2}$ and six consecutive respiratory $^{1}$ cycles (see table). The inspiration-

Inspiration-expiration differences of one and six respiratory cycles

\begin{tabular}{lcccc}
\hline & $9 \mathrm{am}$ & $11 \mathrm{am}$ & $\mathrm{p}$ & $\begin{array}{c}\text { Coefficient } \\
\text { of variation }\end{array}$ \\
\hline $\begin{array}{l}\text { Resting heart rate } \\
\text { Inspiration-expiration differences }\end{array}$ & $78(55-95)$ & $73(57-82)$ & $\mathrm{p}-0.001$ & - \\
$\begin{array}{l}\text { (average six cycles) } \\
\text { Inspiration-expiration difference } \\
\text { (one cycle) }\end{array}$ & $20(2-48)$ & $20(1-44)$ & $\mathrm{NS}$ & $9 \%$ \\
\hline
\end{tabular}

Results (in beats $/ \mathrm{min}$ ) expressed as median with range in parentheses. expiration differences of one and six cycles were almost identical both at 9 and $11 \mathrm{am}$. The coefficient of variation of one cycle, however, was much higher than the coefficient of variation of six cycles. We also reanalysed the normal range in 133 healthy subjects previously studied by us. ${ }^{1}$ We found a much wider scatter of values for the inspiration-expiration difference based on one instead of the average of six cycles.

We suggest, therefore, that the average of ix and not one cycle should be used in screening for vagal neuropathy in diabetic patients. There is much to be learnt about factors that influence the tests measuring vagal control of heart rate not related to damage of autonomic nerves. ${ }^{3}$ Hence we propose that a combination of tests is used to establish vagal neuropathy in diabetic patients.

WOUTER WIELING Cornelius Borst

Department of Internal Medicine, Amsterdam, The Netherland

\section{Wieling W, Brederode JFM van, Rijk LG de, Borst C, Dunning AJ. Reflex control of heart rate in normal subjects in relation to age: a data base for
cardiac vagal neuropathy. Diabetologia $1982 ; \mathbf{2 2}$ cardiac \\ Bennett I , Farquhar IK, Hosking DJ, Hampton JR. Assessment of methods for investigating autonomic nervous control of the heart in patients with diabetes mellitus. Diabetes 1978;27:1167-74. \\ Rijk C, Wieling W, Brederode JFM van, Hond A Rijk LG de, Dunning AJ. Mechanism of initial 1982;243: $\mathrm{H} 676-81$}

New thoughts for the Health Education Council

SIR,-I am assured and would in any case have expected that you practise responsible journalism, and I find much in the leading article on the Health Education Council (18 December, $p$ 1761) that indicates your concern for the health of the nation. You choose smoking and alcohol abuse as your targets, to which nearly everyone interested in health education would give top priority. You point to the obvious allies for the council-the health professionals and the politicians. You urge us to court and use the media. If you had had the privilege, as I have, to be part of the council's work for nearly five years you would know that practically everything you urge is a matter for daily concern and action at the council's headquarters.

What disappoints, indeed depresses, me most about your article is that it illustrates a very superficial knowledge of the council's work, its objectives, and how it tries to reach them. It is unjust to make such sweeping judgments when you do not appear to have informed yourself. Even a cursory reading of the council's annual reports and a glance at a booklet on the council's programmes of work would have widened your knowledge.

I could give a tediously long list of the council's endeavours and achievements in the 